\title{
Differenz
}

Revista internacional de estudios heideggerianos y sus derivas contemporáneas

AÑO 1 NÚMERO 0: JULIO DE 2014. e-ISSN: 2386-4877 - DOI: 10.12795/Differenz.2014.i00.11

[pp. 109-115]

\section{Ontología, aleteiología y praxis}

\author{
Alejandro G. Vigo \\ Instituto Cultura y Sociedad (ICS). Universidad de Navarra
}

Mi interés por el pensamiento de Martin Heidegger se remonta a la época de mis estudios de grado en la Facultad de Filosofía y Letras de la Universidad de Buenos Aires, a fines de los '70 y comienzos de los '80. En aquellos años, la carrera de Filosofía tenía una impronta marcada principalmente por la presencia del pensamiento griego, por un lado, y de la filosofía trascendental alemana, en la línea que va de Kant a Heidegger pasando por Husserl, por el otro. Dentro de esa constelación, Heidegger jugaba, como es natural, un papel determinante, entre otras cosas, porque aparecía como el pensador clave a la hora de intentar conectar ambas tradiciones, en particular, en el ámbito de la ontología: Heidegger ofrecía caminos para leer de un modo completamente renovado los textos clásicos del pensamiento ontológico griego, que permitía hacerlos hablar en un lenguaje que resultaba relevante y hasta desafiante para el pensamiento contemporáneo. En sus manos, los textos de los presocráticos y Aristóteles, no tanto los de Platón, se convertían en puntos de referencia fundamentales de un intento de autoesclarecimiento filosófico que revertía, ante todo, sobre los propios presupuestos del pensamiento contemporáneo. Dicho de otro moodo: los textos principales de la ontología griega proporcionaban el punto de partida para una reflexión que ponía en cuestión los prejuicios y los dogmas de lo que había llegado a ser nuestro propio "sentido común" filosófico, es decir, las bases mismas del modo de pensar heredado de las formas crepusculares del gran pensamiento de la Modernidad. El modo en el que Heidegger leía a Parménides, Heráclito o Aristóteles dejaba, pues, en claro por qué el propio Heidegger había podido declarar 
que la "destrucción" de la historia de la ontología anunciada en Sein und Zeit, lejos de tener un sentido negativo respecto del pasado, dirigía su intención crítica, más bien, hacia el presente.

En mi caso, el poderoso impulso filosófico procedente de Heidegger, tal como lo trasmitían las inolvidables clases del Prof. Adolfo Carpio, rápidamente entró en resonancia con el amor por la lengua griega, que alimentó en mí la figura de mi primer maestro, el filólogo Lorenzo Mascialino. Por cierto, Mascialino, en cuya cátedra trabajé como ayudante durante ocho años, nada tenía que ver con Heidegger y lo miraba con el recelo que emanaba naturalmente de su agudísimo olfato de clasicista y su robusto sentido de realidad. Pero toleraba benevolentemente mis devaneos. Por mi parte, aunque sin perder nunca del todo el contacto con la filosofía trascendental alemana, en particular, con Heidegger y Kant, hacia el final de mis estudios de grado, estaba decidido ya a ser, al menos, por un tiempo, un helenista. Pero en esa decisión Heidegger seguía jugando un papel motivador fundamental. De hecho, el progresivo acercamiento a Aristóteles, que iba a ser mi autor de referencia en la década siguiente, no podría explicarse sin la mediación de Heidegger, en particular, a través de la notable interpretación de la concepción aristotélica del tiempo que se desarrolla en la parte final de la lección contenida en el tomo 24 de la Gesamtausgabe. El Prof. Carpio dedicó el curso de metafísica del año 1982 al tema "Ser y tiempo en Heidegger y Aristóteles". Asistí como alumno del último año de carrera e hice una primera traducción, precaria y vacilante, del texto de Física IV 10-14. La elección de mi tema de tesis de licenciatura, que versó sobre la conexión entre tiempo y sustancia en Aristóteles, vino directamente motivada por el modo en el que Heidegger leía el tratado aristotélico del tiempo, como una suerte de testimonio documental de la concepción griega del ser. A la vez, mi pertenencia al ámbito filológico se concretaba a través de mi adscripción, en calidad de ayudante, a la cátedra de Griego, primero, y, luego, tras el regreso del Prof. Conrado Eggers Lan a la Universidad de Buenos Aires en 1985, también a la cátedra de Historia de la Filosofía Antigua. Esa pertenencia me obligaba, por así decir, a intentar proceder como lo hacen los verdaderos scholars, cuando del estudio de los griegos se trata. De ahí emanaban, por tanto, restricciones metódicas muy precisas, que me ayudaron a esforzarme por tomar conciencia de los riesgos e intentar definir, en un proceso que no estuvo libre de tropiezos, lo que me parecía ser el modo más adecuado de canalizar los impulsos procedentes de Heidegger. Fui comprendiendo, cada vez con más nitidez, que la genuina admiración por la potencia filosófica de Heidegger y la sana acogida de su innegable capacidad de inspiración no debían degradar jamás, como por desgracia lo hacían tan frecuentemente, en ninguna forma de seguimiento dogmático de sus interpretaciones ni mucho menos en una absurda mistificación de los orígenes griegos, 
tampoco naturalmente, de la propia lengua griega de la época clásica. Los ejemplos negativos, tan abundantes entonces como lo son todavía hoy, lamentablemente, también me fueron de gran ayuda, porque me permitieron, creo, definir con mayor claridad lo que, a mi juicio, no se debía hacer, en el tránsito por el resbaladizo terreno de la confluencia entre Heidegger y los griegos.

Si en un primer momento fue la temática vinculada con el papel del tiempo en la ontología aristotélica la que, de la mano de Heidegger, ocupó el centro de mi interés, en un segundo momento, a partir de mi traslado a Alemania a fines de 1988, se fue abriendo paso con cada vez mayor decisión el interés por la concepción aristotélica de la praxis. Aquí el impulso de Heidegger continuó siendo decisivo. Pero hay dos vertientes que explican mejor cómo y por qué.

La primera tiene que ver con el descubrimiento del impresionante libro del Prof. Wolfgang Wieland sobre la física aristotélica, una obra que, aparecida por primera vez en 1962, se convirtió muy pronto en un verdadero clásico. Wieland lee la física aristotélica en una clave que combina, de modo un modo notablemente creativo e inspirador, lo mejor de los aportes de las dos tradiciones dominantes en la filosofía de su época: la tradición de la filosofía analítica, por un lado, y la tradición fenomenológica, también en su vertiente hermenéutica, por el otro. Descubrí el libro hacia 1984 o 1985, calculo, cuando empezaba a trabajar en mi tesis de licenciatura $y$, paralelamente, en una traducción comentada de los libros III y IV de la Física, como parte de un proyecto más amplio compartido con mi amigo el Prof. Marcelo Boeri, compañero de estudios en la UBA desde los comienzos a fines de los '70. El libro de Wieland me impactó de un modo que no puedo describir adecuadamente, sobre todo, por la impresionante exhibición de conciencia metódica y profundidad filosófica que ponía de manifiesto poco menos que en cada página. En ese momento se imponía ya, también en Buenos Aires, la moda según la cual la única filosofía digna de tenerse en cuenta era la procedente de la tradición analítica anglosajona. Y mucha gente veía el libro de Wieland, sin más, como una obra perteneciente a esa tradición, por el simple hecho de que daba una importancia central al papel lenguaje en la interpretación de la concepción aristotélica de los principios. Para mí era claro, sin embargo, que el libro en modo alguno podía considerarse como la obra de un representante ortodoxo de la nueva corriente en boga. Lo que personalmente me impactaba de Wieland era, justamente, la imposibilidad de adscribir su modo de entender la filosofía a ninguna escuela determinada, y su enorme capacidad para incorporar todo lo que resultara filosóficamente relevante y fructífero, con total lucidez respecto de los precios que se debe pagar en cada caso, cuando se apela a tal o cual tipo de instrumento conceptual. Por lo demás, me parecía evidente que la procedencia de Wieland estaba 
en la tradición del pensamiento fenomenológico y hermenéutico. No sólo se había doctorado con Gadamer, sino que además, como pude comprobar tiempo después, su tesis, escrita hacia fines de los '50 y dedicada al pensamiento tardío de Schelling, tenía una clarísima impronta heideggeriana. En ese escrito inicial, compuesto a una edad poco menos que infantil, pues el autor tenía sólo 23 años en el momento de la publicación (1956), la dependencia de Heidegger era todavía excesiva, seguramente, por la simple falta de tiempo para una asimilación más madura y distanciada. Pero en el libro sobre la física de Aristóteles, publicado sólo seis años más tarde, ya no quedaba nada de esa transitoria indigestión juvenil, al punto de que la decisiva influencia de Heidegger puede pasar poco menos que inadvertida para quien proceda de otras tradiciones filosóficas. A mí me resultaba claro, sin embargo, que lo que hacía Wieland con Aristóteles no podía comprenderse adecuadamente sin tomar en cuenta los decisivos impulsos provenientes de Heidegger. Y pude confirmarlo más tarde de modo directo, pues el impacto que me produjo la obra fue tal que me llevó a tomar la decisión de trasladarme a Heidelberg para poder estudiar con el autor.

Al llegar a Heidelberg a fines de 1988 mi intención era escribir una tesis doctoral sobre la concepción aristotélica del tiempo físico, vale decir, en el marco de la teoría del movimiento natural. Aunque inicialmente había aceptado mi plan, el Prof. Wieland, sin embargo, me disuadió y me sugirió abordar la cuestión del tiempo en un área diferente de la filosofía aristotélica, a saber: en el marco del análisis de la praxis y sus estructuras fundamentales, tal como Aristóteles lo lleva a cabo en su filosofía práctica. El tema me resultaba mucho más difícil por dos razones elementales: primero, porque, a diferencia de lo que ocurre en sede física, Aristóteles no desarrolla de modo expreso, en sede ética, una teoría del tiempo propio de la praxis; segundo, porque yo había estudiado mucho más la filosofía natural y la ontología de Aristóteles que su filosofía práctica. Y es aquí donde se inserta la referencia a la segunda vertiente que mencioné más arriba. El asunto tiene que ver nuevamente con Heidegger, pero esta vez en conexión con la obra del Prof. Franco Volpi, brillante estudioso y amigo inolvidable. Hacia 1985, estando todavía en Buenos Aires, llegó a mis manos por intermedio de un colega que era amigo de Volpi su libro pionero sobre Heidegger y Aristóteles, recientemente aparecido. Escribí entonces una reseña que apareció tiempo después en la Revista Latinoamericana de Filosofía. Ya en Alemania me encontré con los artículos de 1988 y 1989, igualmente pioneros, en los que Volpi proponía la osada tesis que hizo famosa su lectura del Heidegger temprano, a saber: la que veía en la concepción de Sein und Zeit una suerte de radicalización, en clave ontológica, de las estructuras fundamentales avistadas por Aristóteles en su tratamiento de la praxis. La conexión entre ontología y praxis, evidente para cualquiera ya en una 
primera aproximación a Sein und Zeit, aparecía ahora, al mismo tiempo, como el resultado de una audaz apropiación transformadora de la concepción de la acción y la vida humana elaborada por Aristóteles en su filosofía práctica. En el libro Volpi comentaba, además, el modo en el que Heidegger interpretaba el tratado aristotélico del tiempo de Física IV 1014 , buscando las huellas que documentaban de modo indirecto el papel posibilitante de la temporalidad originaria. Sobre esta base, la pregunta que se me planteaba era obvia: si lo que sugería Volpi sobre el papel de la concepción aristotélica de la praxis era cierto, ¿por qué, en el caso del tiempo, Heidegger no había buscado lo que quería encontrar en la ética de Aristóteles, más bien que en la física? ¿Por qué dirigía contra Aristóteles el reproche de haberse limitado, en definitiva, a llevar al plano del concepto la concepción vulgar del tiempo, orientada a partir del uso del reloj? Siguiendo los impulsos procedentes de la propia operación interpretativa llevada a cabo por Heidegger en Sein und Zeit, ¿no se podía intentar reconstruir la visión del tiempo subyacente a la concepción aristotélica de la praxis, desde Aristóteles mismo y sin heideggerianismos, a fin de emplearla, a la vez, como hilo conductor para el esbozo de una ontología de la praxis, que no se dejara reducir a la ontología que el propio Aristóteles elabora para dar cuenta de la naturaleza y el movimiento natural? La confluencia de todos estos elementos y motivos explica el origen del proyecto que intenté llevar a cabo en la tesis doctoral, cuya versión publicada en 1996 lleva el título Zeit und Praxis bei Aristoteles.

La conexión entre ontología y praxis ganó protagonismo, pues, en los años de la tesis doctoral. Pero la explicación biográfica tiene aquí, como suele ser el caso, el orden inverso del que reclamaría una explicación de índole puramente conceptual. No en vano insistía el propio Aristóteles sobre la asimetría entre el orden de la adquisición y el de la justificación del conocimiento: "lo primero para nosotros es lo último por naturaleza". En efecto, llegué a la conexión entre ontología y praxis del modo que acabo de explicar. Y sólo más tarde pude advertir con más claridad que el término medio que hacía posible la vinculación de ambos ámbitos había que buscarlo en la noción de verdad, tomada en el sentido radicalizado y ampliado que en los años de gestación de Sein und Zeit Heidegger intenta recuperar, una vez más, de la mano de Aristóteles. La radicalización heideggeriana consiste, como se sabe, en la recuperación del sentido esencialmente manifestativo de la verdad, entendida como alétheia, en el sentido que, con o sin razón desde el punto de vista histórico-filológico, Heidegger atribuye al término. Se trata, en definitiva, de una cierta recuperación de la noción de verdad trascendental, tal como fue elaborada en la tradición metafísica que conduce incluso hasta Kant y Hegel: la verdad como la apertura originaria del ente a la comprensión o, si se prefiere, como la venida a la presencia del ente, para emplear una metafórica recurrente en el propio Heidegger. En el caso de Heidegger, tal 
radicalización hace coextensiva, a la vez, a la verdad, en su sentido trascendental, con la experiencia de sentido, en todas sus posibles formas. Por lo mismo, trae consigo también una drástica ampliación del ámbito de la verdad trascendental: todo posible modo de acceso al ente, vale decir, también el que tiene lugar a través del trato práctico-operativo, debe verse como un modo del "ser en la verdad", como rasgo constitutivo del "existir" del Dasein, es decir, de su "ser en el mundo". De este modo, la praxis queda (re)incorporada ella misma al ámbito de la verdad. Así lo había sugerido ya el propio Aristóteles con su concepción de la verdad práctica, tal como aparece desarrollada en el libro VI de Ética a Nicómaco, un texto fundamental para entender el punto de partida tanto de Heidegger como posteriormente también de Gadamer. Por otro lado, la tesis heideggeriana según la cual la ontología sólo es posible como fenomenología pone en el centro del interés ontológico la problemática verdad trascendental. Como había mostrado Emil Lask, el autor predilecto de Heidegger en los tiempos de la primera época de Friburgo, la lección fundamental del giro copernicano de Kant y de la fenomenología de Husserl viene a ser, en definitiva, una y la misma, a saber: la ontología, rectamente entendida, no puede ser sino aleteiología, es decir, un lógos sobre las condiciones de posibilidad de la apertura del ente a la comprensión (alétheia) y, con ello, de la constitución originaria del sentido experimentado, en todas sus posibles formas. ${ }^{1}$

Es, pues, en el contexto más amplio de una reformulación radicalmente aleteiológica de la problemática ontológica donde el acceso práctico-operativo puede adquirir la centralidad que muestra en la concepción presentada en Sein und Zeit. Pero esto abre también nuevas perspectivas para la consideración de la praxis misma, pues pone las bases de un modo de aproximarse a la acción que sitúa en el primer plano de la atención el entramado total de sentido que sustenta la genuina praxis, la cual resulta ella misma irreductible al sustrato kinético y causal que vehiculiza y expresa dicho sentido, al buscar realizarlo en la exterioridad. En un pasaje famoso de Brief über den Humanismus (1946), Heidegger se queja amargamente de que aún no hemos aprendido a pensar verdaderamente el "obrar" (Handeln), porque lo pensamos primariamente a partir de la producción de efectos (Bewirken einer Wirkung), cuando su esencia tiene más bien el carácter del llevar a cabo, en el sentido propiamente realizativo del acabamiento (Vollbringen). Como se sabe, en

\footnotetext{
1 No podría reseñar aquí todas las contribuciones que me ayudaron a encontrar el hilo conductor en lo que se me aparecía como un verdadero laberinto. Pero no puedo dejar de mencionar los trabajos señeros de dos intérpretes de la talla del Prof. Ramón Rodríguez y el Prof. Steven Galt Crowell, a los que tengo, además, por amigos. Tampoco puedo omitir la mención del Prof. Roberto Walton y el Prof. Alberto Rosales, dos verdaderos maestros del pensamiento fenomenológico, de quienes aprendí, de diversos modos, muchas cosas, que, en ocasiones, han sido decisivas en la búsqueda de mis propios caminos.
} 
una lección dictada en 1930, Heidegger reprocha a Kant haber ofrecido el mismo tributo en el altar de la efectuación, al intentar pensar la libertad desde la causalidad, y no desde la trascendencia del Dasein. Sin embargo, al igual que en el caso de Aristóteles, es el propio Heidegger, con su insistencia sobre la imposibilidad de reconducir el obrar al ámbito de la mera efectuación, el que abre nuevas vías también para una renovada interpretación de la concepción kantiana. Dicha interpretación debería apuntar a recuperar aquellos aspectos que documentan una visión del obrar que no se deja circunscribir en los límites de la mera eficacia, justamente, en la medida en que parte del reconocimiento del carácter prioritario e irreductible del entramado de sentido que sustenta a toda genuina práxis. En tal sentido, mis empeños de los últimos años, intermitentes e inconclusos, por reconstuir de modo más integral los fundamentos de la concepción kantiana de la acción reconoce, una vez más, una clara inspiración heideggeriana, y ello también en lo que pudieran tener de crítico respecto del modo en el que Heidegger lee algunos de los aspectos centrales de la filosofía práctica de Kant.

No podría reseñar aquí todas las contribuciones que me ayudaron a encontrar el hilo conductor en lo que se me aparecía como un verdadero laberinto. Pero no puedo dejar de mencionar los trabajos señeros de dos intérpretes de la talla del Prof. Ramón Rodríguez y el Prof. Steven Galt Crowell, a los que tengo, además, por amigos. Tampoco puedo omitir la mención del Prof. Roberto Walton y el Prof. Alberto Rosales, dos verdaderos maestros del pensamiento fenomenológico, de quienes aprendí, de diversos modos, muchas cosas, que, en ocasiones, han sido decisivas en la búsqueda de mis propios caminos. 